University at Albany, State University of New York

Scholars Archive

University Libraries Faculty Scholarship

University Libraries

2021

\title{
Teaching with Intent: Applying Culturally Responsive Teaching to Library Instruction
}

\author{
Priscilla Seaman \\ University at Albany, State University of New York, pseaman@albany.edu \\ Chapel Cowden \\ University of Tennessee at Chattanooga, chapel-cowden@utc.edu \\ Sarah Copeland \\ University of Tennessee at Chattanooga, sarah-copeland01@utc.edu \\ Lu Gao \\ University at Albany, State University of New York, Igao@albany.edu
}

Follow this and additional works at: https://scholarsarchive.library.albany.edu/ulib_fac_scholar

Part of the Library and Information Science Commons

\section{Recommended Citation}

Seaman, Priscilla; Cowden, Chapel; Copeland, Sarah; and Gao, Lu, "Teaching with Intent: Applying Culturally Responsive Teaching to Library Instruction" (2021). University Libraries Faculty Scholarship. 141.

https://scholarsarchive.library.albany.edu/ulib_fac_scholar/141

This Article is brought to you for free and open access by the University Libraries at Scholars Archive. It has been accepted for inclusion in University Libraries Faculty Scholarship by an authorized administrator of Scholars Archive. For more information, please contact scholarsarchive@albany.edu. 


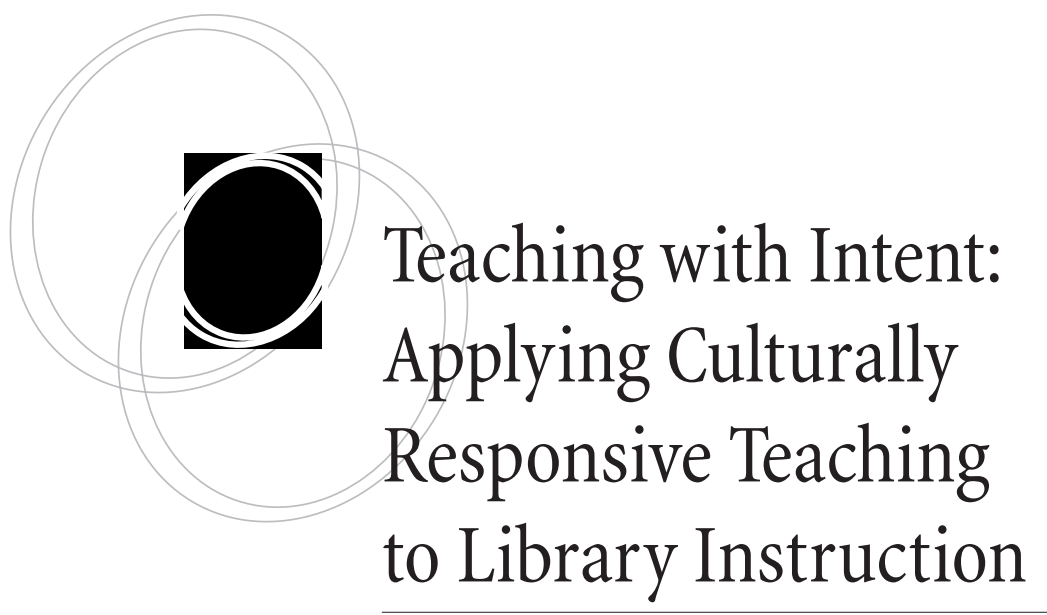

Chapel Cowden, Priscilla Seaman, Sarah Copeland, and Lu Gao

abstract: Despite increasingly diverse classrooms, librarians may teach to the middle without considering the divergent experiences of the actual students in the class. Additionally, the centrality of whiteness in academia and librarianship may contribute to a lack of inclusivity in the library instruction classroom. Culturally responsive teaching (CRT) provides a framework for realizing inclusivity for culturally diverse students. This article presents theoretically grounded, practical applications of CRT for the library instruction classroom within three suggested areas for improvement: preparation, communication, and facilitation.

\section{Introduction}

L ibrarians can improve their instruction by implementing principles of culturally responsive teaching (CRT) in their classrooms. CRT is a pedagogy that recognizes the need to "filter curriculum content and teaching strategies through [students]' cultural frames of reference." ${ }^{1}$ CRT as an organized pedagogical approach is not a new concept in American education. Gloria Ladson-Billings and Geneva Gay first articulated this theory over 20 years ago for $\mathrm{K}-12$ education, and a substantial literature developed around implementing CRT with this population. Higher education was slower to adopt CRT and only recently started to address it in the academic library instruction literature. As American institutions of higher education continue to confront the barriers to student success, it has become increasingly clear that educators must recognize cultural hurdles imposed by educational systems. Library instruction programs, as an essential partner in the academic success of students, would benefit from the potential of CRT 


As American institutions of
higher education continue
to confront the barriers
to student success, it has
become increasingly clear
that educators must recognize
cultural hurdles imposed by
educational systems.

to improve student learning outcomes, enhance classroom climate, and engage more learners. Implementing CRT in the library classroom also has the potential to contribute to institutional metrics of success, such as student retention and progression. Moreover, CRT is a tool that may help academic librarianship overcome the whiteness that pervades the profession. ${ }^{2}$

Yet, a significant challenge facing librarians is that many CRT techniques are intended for a semester- or yearlong course in which instructors can effectively develop relationships with students. How can instruction librarians imple-

ment CRT when faced with the limitations of the "one-shot" library teaching session and other challenges? The one-shot format poses barriers to incorporating CRT, such as the difficulty of knowing students' cultural backgrounds prior to class and insufficient time to build relationships between the librarian and students. Limitations may also result from the librarian's lack of training or awareness related to cultural differences.

\section{While it is vital to recognize the different cultures and languages in our classrooms, students vary in ways beyond this traditional understanding.}

Importantly, aligning too closely to the original articulation of culturally responsive teaching may also limit the instruction librarian because CRT is rooted in theories of cultural and linguistic diversity. ${ }^{3}$ While it is vital to recognize the different cultures and languages in our classrooms, students vary in ways beyond this traditional understanding. They are not only culturally and linguistically diverse; they differ in a multitude of other ways, including in their gender identity and sexuality, their ability, and more. How can librarians employ culturally responsive teaching despite these challenges?

Elizabeth Foster's 2018 article "Cultural Competence in Library Instruction: A Reflective Practice" is one of the few published explorations of how CRT can inform our practice as instruction librarians. In addition to an extended review of relevant literature from across the academy, Foster provides steps to implement reflective practice, the process of looking back and reflecting on one's actions, to enhance the cultural competence of the instruction librarian. ${ }^{4}$

The current article builds on Foster's work by providing a practical guide to integrating culturally responsive teaching into the library instruction classroom. The authors will present three areas in which CRT has the potential to enhance the library classroom: deepening self-awareness (preparation), effective expression (communication), and decentering the instructor (facilitation).

\section{Literature Review}

The following literature review provides an overview of the works of the original theorists of culturally responsive teaching, followed by a review of the literature of CRT in higher 
education. It concludes with CRT in library literature, specifically in library instruction. For consistency and readability, the authors use the term culturally responsive teaching (CRT) to include several closely related theories.

Culturally responsive teaching is rooted in theories of critical pedagogy, multiculturalism, and feminist pedagogy, among others. The works of Paulo Freire, the foundational theorist of critical pedagogy, are widely cited in the CRT literature. Freire questioned traditional teaching models that posited the teacher as sole authority who transmitted knowledge to students in a one-way monologue. Instead, he advocated for a dialoguebased student-teacher relationship in which educators take on the role of facilitators, allowing students to discover the world for themselves and to value and incorporate their own cultures and experiences. Further, he described how the forces of colonialism and power structures shape the curriculum, behaviors, and minds of educators and students alike. Freire pointed to the close links between education and sociopolitics, and argued for a teaching praxis that enables students and teachers to develop a critical consciousness through reflection and action. ${ }^{5}$ Freire's ideas are woven throughout CRT.

In 1995, Gloria Ladson-Billings distinguished culturally responsive teaching from other pedagogies in its cultural and linguistic foundation. ${ }^{6}$ The practice of CRT embraces cultural background as essential to student engagement. Ladson-Billings asserted that incorporating cultural references into all aspects of learning both provides a bridge from students' experience to the mainstream culture and validates their ethnic backgrounds and life experiences. ${ }^{7}$ Ladson-Billings, who grounded her work in Black feminist thought, focused on K-12 teachers of African American students. She described those studying to become teachers "primarily as ... young, middle-class, White females," ${ }^{8}$ a K-12 teaching demographic that persists today. ${ }^{9}$ In higher education in 2017, the majority of full-time professors were white males ( 41 percent), followed by white females (35 percent). ${ }^{10}$

The purpose of CRT is to achieve "equitable educational outcomes for all students" and to improve academic performance. ${ }^{11}$ Ladson-Billings proposed that culturally responsive teaching meets three criteria: (1) an ability to develop students' academic success; (2) a willingness to nurture and support cultural competence; and (3) the development of sociopolitical or critical consciousness. ${ }^{12}$ It is crucial for teachers to motivate students to pursue academic excellence and to transmit knowledge. Culturally responsive teaching empowers students to use their cultural knowl-

Culturally responsive teaching empowers students to use their cultural knowledge and experiences as "a vehicle for learning." edge and experiences as "a vehicle for learning."

Beyond academic success and cultural competence, critical consciousness helps students cultivate a "broader sociopolitical consciousness" that enables them to critique social values and cultures. ${ }^{13}$

Geneva Gay followed Ladson-Billings with an influential book about culturally responsive teaching, updated twice, most recently in 2018. ${ }^{14}$ Inspiration for Gay's original writings came from the theories of cultural pluralism and multicultural education, particularly the works of James Banks. ${ }^{15}$ Multiculturalism in education emerged as a reaction to the "melting pot" philosophy of early- and mid-twentieth-century America and as an outgrowth of the civil rights movement of the 1960s and 1970s. ${ }^{16}$ Like CRT, 
the early literature of multicultural education focused on $\mathrm{K}-12$. While CRT builds upon theories of multiculturalism, it focuses on the potential of cultural distinctions, rather than the blending of many cultural expressions in American society.

Geneva Gay argued that traditional education asked students and teachers to adopt an attitude of "cultural blindness." A Eurocentric approach to education, regardless of a teacher's cultural background, hurts students of color. This attitude of Eurocentrism originated from the following notions: (1) that education is not related to cultural background; (2) that education provides an entrée into the mainstream; and (3) that students reject diversity in favor of adaptation to United States society. ${ }^{17}$ Gay contended that students' cultures and experiences should be embraced rather than ignored, and she held that teaching which incorporates diverse cultures and frames of reference results in improved performance and achievement among underrepresented students. Gay also asserted that "academic success and cultural consciousness are developed simultaneously."18

As CRT gained traction in the K-12 setting in the mid-1990s and early 2000s, colleges and universities followed suit. Educators and administrators pointed to the growing diversity in college student demographics. In 1998, a group of professors published a collection of essays on university multicultural education with a transdisciplinary view. They contended that "in an ethnically plural society ... courses must reflect the amalgam of the cultures of the people who comprise that society." 19 A 2009 book by Margery Ginsberg and Raymond Wlodkowski examined diversity and motivation, looking specifically at the application of CRT in college teaching. The authors captured two key concepts of culturally responsive teaching: the ability of all students to succeed, and the instructor's role in creating a climate in which students have confidence, motivation, and belief in their abilities to achieve academic success. ${ }^{20}$ Extending this work, Patricia Larke introduced models of CRT in higher education and provided ideas for applying culturally relevant assignments and practices throughout a semester-long class. ${ }^{21}$

Scholars in higher education also discussed theories and practices in which college curricula should promote understanding of race, class, and sociocultural identity. ${ }^{22}$ While many works on CRT in higher education focus on teaching practices and pedagogies, a set of essays edited by Lorri Santamaría and Andrés Santamaría examined the role of culturally responsive leadership in promoting access and equity in higher education. ${ }^{23}$ Another set of essays, titled Culturally Responsive Teaching and Reflection in Higher Education, resulted from an intensive cultural literacy institute. These essays called on faculty to "build diverse, equitable teaching/learning environments" and to be "reflective, aware, and intentional in their teaching." ${ }^{24}$ Related to CRT, a "funds of knowledge" approach draws upon students' experiences and cultures as classroom resources and strengths. ${ }^{25}$ While most of the literature of CRT in higher education offers theories and practical applications, one study looked not only at CRT's acceptance and implementation in higher education but also at ways in which it had met resistance. ${ }^{26}$

In library and information science, information literacy provided a focused space for discussing and incorporating theories related to CRT. These theories included critical pedagogy, which encourages students to question and challenge inequalities in society, and critical information literacy (CIL), which fosters a questioning attitude toward information, especially its political, social, and economic dimensions. Alison Hicks used foreign language study as an example of a field in which learning goals, such as internationalization and global knowledge, coincided with critical information literacy. 
While Hicks did not explicitly refer to CRT in her article, her conclusion captured its spirit: "The CIL classroom provides a safe space to consider differences in meaning and worldview, thereby actively contributing to goals of transcultural competence."27

Kimberly Pendell and Robert Schroeder described a partnership in which librarians worked with teaching faculty and administrators to help support diversity and inclusion initiatives on campus. Among other objectives, the initiatives specifically pointed to improving cultural responsiveness. The project resulted in the creation of a LibGuide for CRT materials and resources, and a mutually enlightening dialogue between librarians and teaching faculty. ${ }^{28}$

Funds of knowledge, mentioned earlier, is a corollary concept to CRT. Amanda Folk presented case studies in which a funds of knowledge approach was applied to a research assignment for first-generation students, connecting students' identities and lived experiences to the assignment. When given the opportunity to choose topics meaningful to them, students demonstrated greater intrinsic motivation, and in the process, developed information literacy skills and a better understanding of academic culture. ${ }^{29}$

Elizabeth Foster's 2018 article most closely addressed concepts of CRT and its application in library instruction. Foster focused on "cultural competence," one of the three CRT cornerstones enumerated by Ladson-Billings, and sought ways in which "instruction librarians will be better prepared to connect with and teach students from a variety of backgrounds." While the majority of Foster's article centered on models of teaching, such as reflective practice and self- and other-awareness, she also discussed instructional design and assignment creation as ways to incorporate cultural competence. Foster emphasized the importance of integrating cultural competence in all elements of instruction, from preparation to delivery, reflection, and revision. ${ }^{30}$

\section{Applications of Culturally Responsive Teaching}

Building upon the foundational theorists and practitioners of culturally responsive teaching and related theories, as well as the theoretical framing for library instruction provided by Foster, this article proposes practical applications of CRT for librarians. Applying CRT to existing library instruction practices requires only minor modification and is compatible with a wide variety of instruction methods. Indeed, incorporation of the proposed methods can be accomplished with subtle shifts or heightened awareness in given areas. Intentionality is key.

Three primary areas of improvement are suggested: preparation, communication, and facilitation. Preparation explores the cultural landscape and beliefs of the individual instructor and offers suggestions for deepening cultural awareness. Communication covers culturally responsive practices that enhance teaching and learning in the diverse classroom. Facilitation delves into methods for decentering the instructor and empowering culturally diverse students to draw from their experiences and backgrounds. Each suggested area of improvement offers several techniques or methods librarians might apply to enhance their practice, labeled "In Practice" in the spirit of Geneva Gay's "Practice Possibilities." ${ }^{31}$ Many teaching librarians already utilize some of the practices suggested in the "Communication" and "Facilitation" sections, and ensuring that these methods are inclusive of culturally diverse students is critical to enhancing learning and carrying out the important work of culturally responsive teaching. 


\section{Preparation: Exploring the Self}

In her seminal work on culturally responsive teaching, Geneva Gay described the importance of "culturally responsive caring" and the mechanisms by which such an undertaking is accomplished. ${ }^{32}$ While much of Gay's work resonates, it may be challenging to imagine culturally responsive caring, a highly feminized concept, in higher education. However, knowledge and self-awareness are the foundations Gay suggested for cultivating culturally responsive caring and for realizing CRT in professional practice. ${ }^{33} \mathrm{~A}$ commitment to reflective practice through preparation and iteration is essential in uprooting assumptions, achieving culturally responsive teaching, and continually improving library instruction for all students.

\section{Implicit Biases and the Art of Self-Reflection}

One strategy for uprooting assumptions involves gaining an understanding of how implicit biases affect our perceptions. The Kirwan Institute for the Study of Race and Ethnicity, a research institute at The Ohio State University in Columbus, defines implicit bias as "the attitudes or stereotypes that affect our understanding, actions, and decisions in an unconscious manner." According to the Kirwan Institute, implicit biases are unconscious, automatic, and pervasive. They may not align with declared beliefs, but they affect behavior, and they are malleable..$^{34}$ Implicit biases exist in all library instructors at some time in some way-they are inescapable. While this may at first seem discouraging, remember that implicit biases are malleable-they can be altered. One way to unlearn something that is unconscious and automatic is to spend time on the art of critical self-reflection.

At the Association of College and Research Libraries (ACRL) workshop that sparked this paper, participants were asked to consider assumptions they made about their students. The librarians' self-reflective exercises uncovered some implicit biases, for example:

- "I assume students come to class ready to learn, but there may be barriers preventing their access to instruction such as food insecurity, lack of housing, no transportation."

- "I make assumptions about my students based on their appearance, and I am now realizing these assumptions may not be accurate."

- "The reminder that students don't necessarily approach education from the same place that I do."

- "I assume they [students] have an existing foundation of knowledge about U.S./ Euro[pean] history ... I generally assume they are going to agree with some scientific modes of thinking/knowledge ... My default is to assume no vision or hearing disabilities." 35

Reflecting upon the assumptions we make about students and how those ideas are largely based upon our narrow lenses and experiences can be embarrassing. Regardless of the discomfort experienced when we practice critical self-reflection, it is imperative that we continually do so to identify our assumptions and eliminate their effects in our classrooms. Self-reflection cultivates critical consciousness and creates an environment conducive to learning for all students. 
Little has been published on implicit bias in library instruction, but some examples of other common assumptions are beliefs about levels of knowledge among millennials, about students' ability with digital tools (including the Internet), and about learning

\section{Regardless of the discomfort experienced when we practice critical self-reflection, it is imperative that we continually do so to identify our assumptions and eliminate their effects in our classrooms.} styles and approaches to education by nontraditional learners, ethnically diverse students, athletes, first-year students, or English as a second language (ESL) students. Some tools assist in identifying underlying assumptions and biases. The most notable example is the Harvard Implicit Association Tests. These tests provide a mechanism to determine if the test taker has an unconscious bias related to any number of groups. ${ }^{36}$ The tests are limited in scope, however, and are not sufficient for library instructors who wish to explore deeper levels of assumption and bias.

To deepen understanding of assumption and bias and their effects upon our teaching, librarians must be unafraid of self-examination and committed to change. Char Booth expresses a similar sentiment, saying, "Being an educator is about laying yourself on the line, opening up to criticism, and accepting vulnerability so that others may gain knowledge; every learning interaction becomes an opportunity to stretch or flinch." ${ }^{137} \mathrm{We}$ find ourselves in this situation while pursuing the work of enhancing cultural awareness. It may be difficult at times, and mistakes will be made. The first, and sometimes the most challenging, part of this process is to examine our cultural context, comprised of our own backgrounds and behaviors.

\section{Applying Self-Reflection for Culturally Responsive Teaching}

Offered here are introductory exercises to begin the work of critical self-reflection and to prepare library instructors for classroom applications of culturally responsive teaching. Many of the materials, including the following self-reflection exercises, were presented at an ACRL workshop. The workshop included discussion after each activity, but the activities can be conducted alone or with a library instruction team. The exercises are meant to jump-start critical self-reflection.

\section{In Practice: The Cultural Artifact}

A cultural artifact, simplistically defined for this exercise, is any remnant of human activity that provides information about the culture of its creators or users. Think of the cultural artifact as a representation of something (an item, a place, a person, or a time) that is important to you and provides some information about who you are. The cultural artifact activity can be utilized for both personal self-reflection and in the classroom with students to explore individual values while appreciating the diversity of experience of others. An example of a cultural artifact might be an old cast-iron skillet. A statement of its importance might be 
My family's cast-iron skillet has been passed down for generations. All the women of my family have used it, and when I use it, I think of their skill in cooking but also of the hardships they endured. I am proud that I am not the only one in my house to use it. My husband and sons share this history and this heirloom, and we live without gendered work.

The cultural artifact activity serves as a gateway to reflection upon individual origins. A worksheet in the Appendix models the cultural artifact activity and the subsequent sections within "Preparation." Another option for recording personal background may take the form of a diary or journal, specifically intended for critical self-reflection. Reflections that are written down may be referred to later, which is important because self-reflection is an iterative process.

\section{In Practice: Identifying Your Cultural Background}

Many definitions of culture exist. The definition offered at the workshop described culture as the ideas, customs, language, social behaviors, values, and habits of a people or society. Culture is not necessarily aligned with or defined by a single aspect of identity, such as ethnicity. All societies maintain cultural norms, and deep critical reflection is often required to uncover important elements of the cultures in which one has been immersed. Examining one's cultural background can feel like a massive undertaking. Who are you? Where did you come from? What are some traditions you hold? Have your cultural identifications changed as you have aged? The goal of this self-examination is to uncover underlying privileges, assumptions, orientations, and beliefs and to deepen awareness of the effects of these characteristics in the classroom. Allow time to reflect upon this larger question: "How would you describe your own cultural background?" Reflections can be recorded on the worksheet or in a journal.

\section{In Practice: Identifying Your Approach to Teaching}

All instructors have an approach to teaching built upon a mix of individual sociocultural experiences and training. While much about an individual's approach is intentional, just as much may be hidden behind cultural norms. To uncover some of the hidden aspects of your teaching, consider and record your answer to the following question: "Can you think of ways that your cultural background might affect your approach to teaching? Or your approach to librarianship (if you do not teach)?" Some examples from the workshop:

I think that Germans tend to be structured and logical, and I often approach teaching in that way-logical and also practical. I'm not sure that my background affects my librarianship, but I've recently been exposed to the POV [point of view] that librarianship represents middle-class, white cultural values-particularly white female values. I suppose I fit in that respect.

On one level, I would like to think I make an effort to call out ways in which my cultural background and positionality influence my approach to both, especially defaulting to the U.S.-centric perspectives, being confined to English language sources, etc. On a much deeper level, though, the academy and the libraries within it are so rooted in a Eurocentric knowledge tradition (emphasis on text, for example), it's hard to separate oneself from it. 
I struggle to find salient examples from nondominant cultures. I'm probably more likely to give the benefit of the doubt to a white student. I don't have to be fluent in as many cultures. I don't have to code switch as often as my students. I think my students should understand that I'm doing what is best for them.

In Practice: Identifying Assumptions

Perhaps the most challenging part of selfreflection is uncovering assumptions made about students. Every instructor who steps into a classroom has preconceived ideasboth conscious and unconscious-about their students' behavior, abilities, backgrounds, prior knowledge, and more. The process of uncovering these assumptions may be difficult, but it can also be transformative.

In the next step in the self-reflection process, consider the assumptions that you make about your students. The prior section on implicit biases covers several statements from workshop participants about some of the presuppositions they made about students. Librarians might consider sharing some of their assumptions with other library colleagues or instructors in a safe, nonjudgmental environment.

\section{In Practice: Mindful Reflection}

Developing an understanding of ourselves and what we bring to the art of teaching is part of appreciating the value of culturally responsive teaching. This work is iterative because reflection is ongoing. There are many methods of incorporating reflection into librarianship. Some library instructors may choose to employ critical self-reflection after each instruction session and include a dimension that specifically explores CRT elements in the classroom as well as pre-class mental preparation. Some instructors write reflections within documents or lesson plans for an individual class. Others keep a work journal dedicated to reflections and coding them. For example, one might maintain a journal and classify work with CRT so that overall incorporation of CRT principles can be viewed in a single place. Identifying attitudes, beliefs, and student expectations and tracking how these are manifested in instructional practices and relational behaviors are ongoing processes. ${ }^{38}$

Another critical incorporation of reflective practice is the need to become educated about other cultures. Explore the demographics of your school and community and look for ways (such as reading, research, discussions, workshops, and local events) to learn about other cultures and groups, especially those in your community. Learning about other cultures and groups on campus can begin with visiting multicultural centers, women's groups, veteran's affairs offices, or LGBTQ+ centers, among others. Many campuses and organizations offer training in working with diverse populations. Taking advantage of these opportunities will allow for deeper critical self-reflection and an enhanced understanding of the needs of varied populations. 


\section{Communication: A Crucial Component}

Geneva Gay states that "communication is always dynamic and complex ... even more so cross-culturally." ${ }^{39}$ It is important for instructors to incorporate culturally responsive teaching because communication, culture, teaching, and learning are intertwined..$^{40}$ Specifically, culture is a primary factor that affects the way people talk, see, think, and interact with one another. Teaching and learning are more effective when librarians acknowledge the impact of culture on communication and education.

\section{In Practice: Prioritize Introductions}

Introductions often form the first formal contact with students and may become perfunctory-name, title, a quick fact or two, repeat. Many instructors assume that students do not care who they are. However, when enhanced with carefully selected personal information, introductions can establish mutual trust between students and the librarian. Personal information need not be deeply revealing but instead could highlight an experience, a story, or other information that humanizes the instructor. For example, one of the authors of this article introduces herself by relating her role as a librarian, her additional teaching areas, and the number of years she has taught, as well as her status as a first-generation college student. She discusses her connection to the university, which is her alma mater. This introduction is accomplished in under two minutes. It builds rapport with students and establishes instructor credibility. Trust and contextual authority are classroom centerpieces, but rarely are students given a reason to trust us or see us as research experts.

In addition to providing an enhanced introduction, consider ways in which students might introduce themselves. If a class is small (fewer than 40 students), ask students to give their first name and major to acknowledge them as individuals. With fewer students or more time, consider asking students to share an interesting fact about themselves with

In the culturally diverse classroom, it is important for instructors to learn correct pronunciation of names. Correct pronunciation and spelling of names validate the student. the class. Getting to know students as individuals is more challenging in large classes (over 40). One possibility for a large group is to have students introduce themselves to a neighbor. The instructor can also ask names of students when they are called upon to provide examples, demonstrate, or answer questions. In the culturally diverse classroom, it is important for instructors to learn correct pronunciation of names. Correct pronunciation and spelling of names validate the student.

\section{In Practice: Use Simplified, Clear Expression}

When teaching diverse students, effective instructors appreciate and accommodate similarities and differences among students' cultures. Strategies that may help instructors gauge their own communication habits and remove language barriers include: 
1. Becoming familiar with the words and phrases of students from different cultural groups and developing an understanding of unfamiliar words through self-study, interaction with diverse students and colleagues, or both.

2. Including visual material to supplement written and verbal text. ${ }^{41}$

3. Gaining knowledge of students' culture and ethnicity by taking an interest in them and asking questions, attending campus and student cultural events, and getting involved with campus diversity and multicultural centers.

Other strategies include delivering one concept at a time in a deliberate manner, using simple words and phrases, and providing clear, direct explanations from a universal perspective. Pop culture references, obscure analogies, and colloquialisms are a few examples of communication not universally understood. When applying CRT to library practice, librarians can develop an awareness of habitual words and phrases. Gay points out that the instructor needs to "be conscious of cultural codes and cues embedded in regular habits of teaching communications." ${ }^{42}$

Jargon can create a barrier for all students. Many library instructors no longer use library language such as Boolean operators, but such terms as circulation, reference, and database persist, despite sounding foreign to students. Leo Robert Klein asserted that "the best way to increase the usability of library resources and services is to simplify access and avoid library jargon whenever possible." ${ }^{43}$

One technique for increasing awareness of jargon, colloquialisms, pop culture references, and obscure analogies is to invite a nonlibrary peer to observe communication in an instruction session. Library instruction can be engaging and empowering instead of confusing and overwhelming when librarians acknowledge the existence of jargon and endeavor to simplify it for culturally diverse students.

\section{In Practice: Vary Types of Communication}

International and diverse students often must adapt and adjust their communication styles to the new academic environment of higher education. Library instructors can stay actively informed of diverse students' communication styles, both verbal and nonverbal. Jian Wang and Donald Frank describe several communication styles that impact cross-cultural communication. Some of these include the use of idioms, directness and indirectness, and nonverbal communication. ${ }^{44}$ Library instructors can develop a sensitivity to these styles and vary how they express themselves. For example, avoid idioms when possible. Be aware that, while some cultures value directness, others find indirectness a sign of respect. Librarians can vary their nonverbal style and consciously observe and mirror students' gestures, such as eye contact, posture, and voice pitch.

Incorporating the varied learning modes of all students in teaching is especially important in the CRT classroom. Gay suggests teachers adopt varied types of communication, including written, verbal, visual, tactile, and kinetic modalities, to engage students' strengths..$^{45}$ For example, provide handouts and supplement presentations with images, succinct bulleted lists, and other visuals. Incorporate hands-on activities and innovative exercises such as small-group breakouts, collaboration, and time for reflection. These varied learning modes and teaching styles create a positive culture of learning and help all students comprehend the material. 
Gay suggests that teachers and students develop a cross-cultural dialogue by acknowledging their ethnic identities and valuing other cultures. Giving students the opportunity to express themselves, ask questions, and provide feedback creates an environment of cooperative learning. By taking the initiative to comprehend and deepen understanding of cross-cultural communications, the library instructor can serve as a mentor to facilitate diverse cultural communication. ${ }^{46}$

\section{In Practice: Employ Active Listening}

Active listening is, by this paper's definition, giving full attention to the words and body language of others. Listening closely to students in the classroom allows the instructor to assess learning, adjust instruction when needed, hear diverse voices, and practice culturally responsive caring. Preparation and flexibility are required for the instructor to be receptive to student commentary and to

Listening closely to

students in the classroom

allows the instructor to

assess learning, adjust instruction when needed, hear diverse voices, and practice culturally responsive caring.

adjust instructional direction as student discussion requires. Practicing active listening "can be both mentally and physically taxing for the instructor" 47 and a challenge to apply consistently.

Despite the challenges, active listening can be realized in the library instruction environment. Geneva Gay suggests that instructors "restate comments and ask frequent questions to ensure clarity of meaning and understanding of observed communication behaviors." ${ }^{48}$ Similarly, Joshua Margolis suggests reframing student comments rather than correcting errors, which can be particularly important for diverse learners. Margolis asserts that the "closer you can stick to the students' language, the more you bring them with you." 49 Nonverbal communication elements, such as eye contact, head nodding, and leaning toward the speaker, also help to enhance the active listening experience and provide cues to the student that the professor is interested and engaged in listening.

\section{Facilitation: Decentering the Instructor}

A hallmark of culturally responsive teaching, like many related pedagogies, is for the instructor librarian to assume the role of facilitator, rather than providing solely

When the instructor functions as facilitator, learning is student-centered, which allows for greater student control and an intentional focus upon student needs and preferences for learning. lecture-based, authority-focused instruction. When the instructor functions as facilitator, learning is student-centered, which allows for greater student control and an intentional focus upon student needs and preferences for learning. Decentering also frees the instructor to practice active listening, informally assess comprehension and learning, and adjust instruction mechanisms in real time. The following practical applications of decentralization 
are known in library instruction and should be carefully considered in relation to their incorporation for diverse learners.

\section{In Practice: Incorporate Think-Pair-Share}

The infinitely adapted think-pair-share model proposes a discussion strategy in three steps. First, students think about the question and formulate thoughts of their own. Then they collaborate with others, working in pairs to arrive at a consensus. Finally, they share their ideas with the class..$^{50}$ Think-pair-share is well established in the librarian toolkit and has been an excellent mechanism for low-stress class participation. The think-pair-share strategy aligns with culturally responsive teaching through attention to small group discussion or instruction work and allowing potentially less stressful interactions for diverse students. This strategy also provides extra time for contemplation, which may not necessarily be available during standard classroom discussions. An example of a library instruction think-pair-share might ask students to: (1) think about what characteristics might make a writer an authority; (2) pair up with a neighboring student and discuss what constitutes authority (which can differ dramatically crossculturally); and (3) share your discussion with the class to create a class-constructed definition of authority.

\section{In Practice: Create Authentic Learning Environments}

Authentic learning environments are practiced in many educational settings but are less well known in library instruction. Many of the hallmarks of authentic learning environments may be used by library instructors, even if they are not recognized as such. Authentic learning environments are defined as environments where learning is situated in the context of future use, thus creating the conditions for engagement and critical thinking through demonstration of skills exhibiting utility beyond the classroom. Some examples of authentic learning environment characteristics include authentic tasks (challenging tasks with real-world relevance), authentic context (reflecting how knowledge will be used in real life), access to expert modeling of processes (instruction), exploration of multiple roles and perspectives, and collaborative construction of knowledge. ${ }^{51}$ These elements can be realized in library instruction and should reflect the students in a class. Applying these techniques is time-intensive in preparation but worth the reward of creating enhanced, authentic learning experiences that students can apply in the real world. Authentic learning environments align with CRT through high expectations of learners, authenticity for the student, exploration of varied roles and perspectives, and collaboration.

\section{In Practice: Utilize Problem-Based Learning}

Problem-based learning originated in the medical field in the 1960s and has been widely explored in all areas of education, including library instruction. ${ }^{22}$ Problem-based learning can be used to create an authentic learning environment and represents a rich tool for use in culturally responsive teaching classrooms. While problem-based learning takes a variety of shapes, the literature points to commonalities: learning is student-centered, the problems are ill-structured (intentionally vague, missing components, or too broad) and 
authentic, the teachers act as facilitators, and the students often work in small groups. ${ }^{53}$ These techniques align well with CRT principles.

Problem-based learning can be explored in library instruction by finding authentic questions to explore, such as:

- Do antioxidants have any effect upon cancer?

- What are the impacts of hostile architecture?

- A researcher claims that females can withstand higher levels of pain than males. Is there evidence to support this assertion?

Consider questions carefully and include topics relevant to marginalized and minority populations. After assigning students an authentic question, ask them to focus upon aspects of searching. What was your search process? How did you evaluate what you found? Was there a place that worked better than another for your search? How did Google compare? What voices did you not find? Shift the emphasis away from answering the questions definitively, instead focusing on the process of the search. With enough preparation, problem-based learning is a powerful tool with the potential to create a rich learning experience for all learners.

\section{In Practice: Teach to Empower}

Culturally responsive teaching has proved to empower students academically and socially, enabling them to be "better human beings and more successful learners." 54 Empowerment equates to students believing in themselves and having the confidence and courage to act. Gay insisted that empowerment is realized through supporting student learning, building self-esteem, offering resources and help, and recognizing achievement. ${ }^{55}$ Ira Shor, a pioneer in the field of critical education and coauthor with Paulo Freire, offered a complementary perspective. Shor envisioned empowering education as a "critical, democratic pedagogy" for both the individual and society, with goals to connect "personal growth to public life, to develop strong skills, academic knowledge, habits of inquiry, and critical curiosity about society, power, inequality, and change."56 Gay described culturally responsive teaching that emphasizes intentionality in instruction about "racially, ethnically, culturally, and socially diverse issues and experiences." She asked instructors not to avoid or "sanitize" these issues and stated that "students need

\section{Many of the goals of student empowerment in education can be attained by librarians, even in the shortest of classes.}

guidance and assistance in dealing with cultural diversity, racism, and inequities." ${ }^{57}$

Many of the goals of student empowerment in education can be attained by librarians, even in the shortest of classes. A small adjustment to current librarian practice includes altering example topics. For instance, common topics for English composition courses might include self-driving cars or electronic cigarettes. Instructors could introduce

alternate topics that might be unfamiliar to some students but allow for discussion of social justice issues, such as "What is the 'American Dream,' and is it attainable for all?" or "Is the poverty line too low?" Other potentially rich topics include 
- homelessness;

- hostile architecture, designed to keep homeless people away;

- environmental injustice;

- redlining, the denial of services to consumers based on where they live;

- coal ash disposal and rural populations;

- racial disparity in cancer survival; and

- food insecurity on college campuses.

Topics can be concept-mapped to delve deeper (and assist students with narrowing topics) and used in demonstrated searching. Students could leave class with a variety of skills, as well as a broader perspective of social justice and perhaps a deeper understanding of their peers.

\section{Reflections and Conclusions}

\section{Challenges}

As mentioned throughout, the principles and practices of CRT originated in the $\mathrm{K}-12$ environment. This presents some challenges in applying the theory in higher education due to the differing goals and teaching practices in these two educational spheres. The majority of CRT research has been conducted with $\mathrm{K}-12$ students and teachers, creating questions of reproducibility in the postsecondary environment. On the other hand, CRT provides a rich opportunity for exploration and application in colleges and universities, especially in supporting crucial initiatives to promote equity, inclusion, and diversity. The knowledge of and acceptance of CRT in higher education are growing, as evidenced in the literature review.

Applying CRT in college-level library instruction classes presents special and additional challenges, particularly in the common one-shot session. Patricia Larke created a teaching model to incorporate CRT in a semester-long class, but how can library instructors condense such techniques to a one-hour class taught only once per semester? ${ }^{58}$ Culturally responsive teaching relies heavily on building relationships, getting to know students' cultural and linguistic backgrounds, and incorporating their lived experiences into the lesson plan. Again, this presents a challenge for library instructors. Library instructors also must deliver required content that matches professors' expectations and specific assignments, which can further limit their control over the class flow.

The authors address some of these limitations by elaborating on three areas of improvement-preparation, communication, and facilitation-in which small changes can transform the routine teaching practices

Culturally responsive teaching relies heavily on building relationships, getting to know students' cultural and linguistic backgrounds, and incorporating their lived experiences into the lesson plan. of librarians. Pre-class preparation, such as reflection and sensitivity to cultural diversity, help instructors develop self-awareness skills. These can become second nature and "baked into" each library instruction session 
regardless of the traditional limitations of the one-shot. Similarly, developing deeper communication approaches that speak to all students can help ease the challenge of relationship-building between instructors and students. Facilitation practices offer concrete ways to decenter the instructor and engage students in ways meaningful to them.

Culturally responsive teaching can, with work, be applied to information literacy instruction. It provides an excellent vehicle for teaching information literacy because all information has cultural context. Centralizing students as fully engaged partners in creating a culturally responsive learning environment is a keystone of CRT principles that can result in academic success. By embracing and practicing CRT, teachers can make learning dynamic, lifelong, and ever-evolving for both students and themselves.

\section{Future Directions}

The work of culturally responsive teaching is challenging, and the potential is not yet fully realized in library instruction. Further, the paradigm is limited in definitions of culture and excludes an array of students. Many of our institutions do not mirror the populations of surrounding communities. Librarians, therefore, must endeavor to recognize the realities of the students who enter their classrooms. Learners are not only culturally, ethnically, and linguistically diverse; they are also gender diverse, neurologically diverse, varied

Learners are not only
culturally, ethnically, and
linguistically diverse; they
are also gender diverse,
neurologically diverse,
varied in their identity and
sexuality, their ability and
disability, and more.
in their identity and sexuality, their ability and disability, and more. Embracing this panoply and extending the good work of culturally responsive teaching to increasingly varied groups of students is one of the next great challenges.

Another area ripe for further exploration is the application of CRT to assessment of library instruction. Despite best intentions for neutrality, libraries and librarians have biases; likewise, assessment methods are neither neutral nor unbiased because they reflect a cultural context. ${ }^{59}$ Gay argued that an important aspect of the culturally responsive classroom is identifying assessment methods that allow learners to demonstrate competency by using familiar communication methods drawn from their diverse cultural backgrounds. She encouraged instructors to consider a wide variety of verbal, written, visual, and action tools as indicators of student learning. Gay emphasized that no single assessment tool is appropriate for all classrooms; rather, instructors should allow students' cultural contexts to inform selection of tools. ${ }^{60}$ Much work remains to be done to identify assessment methods appropriate for the constraints of the library one-shot that also deepen our understanding of who our students are, how well we connect with them, and whether they achieve learning outcomes.

Potential also exists for CRT to extend beyond the library instruction classroom, in such areas as reference, embedded librarianship, workshops, and asynchronous instruction, delivered without the class meeting face-to-face. Moreover, principles of CRT can be applied beyond teaching environments to improve library services generally. The 
recognition and incorporation of diverse cultural reference points and ways of knowing could transform other user services, such as outreach, student assistant management, and library staff training.

Culturally responsive teaching is an emerging concept for librarians and will require further exploration and application. However, library instruction can be improved immediately through implementing the proposed CRT principles with mindfulness and intent. The principles align with three areas of improvement-preparation, communication, and facilitation - with the understanding that all work in the realm of cultural competency is ongoing. Most suggested alterations do not require drastic modifications but, rather, subtle shifts in practices and ways of thinking. The impact for students, however, can be profound. Seizing the opportunity to make that impact is the first step on the path to culturally competent library instruction.

\section{Acknowledgments}

The authors would like to acknowledge the constructive feedback provided by Professor Dunstan McNutt, instruction librarian at the University of Tennessee at Chattanooga, and Professor Rui Wang, social sciences librarian at Central Michigan University Library in Mount Pleasant.

Chapel Cowden is the health and science librarian and a University of Chattanooga Foundation associate professor at the University of Tennessee at Chattanooga; she may be reached by e-mail at: chapel-cowden@utc.edu.

Priscilla Seaman is the subject librarian for anthropology, geography and planning, and communication and a senior assistant librarian at the University at Albany, State University of New York (SUNY); she may be reached by e-mail at: pseaman@albany.edu.

Sarah Copeland is the director of Desks and Patron Experience and an assistant professor at the University of Tennessee at Chattanooga; she may be reached by e-mail at: sarah-copeland01@ utc.edu.

Lu Gao is a doctoral student in Information Science in the College of Emergency Preparedness, Homeland Security and Cybersecurity at the University at Albany, State University of New York (SUNY); she may be reached by e-mail at: lgao@albany.edu.

\section{Appendix}

\section{"Exploring the Self" Worksheet}

The following worksheet, "Exploring the Self," was used in the workshop "Promoting Learning in the Culturally Diverse Library Instruction Classroom," presented by Chapel Cowden, Priscilla Seaman, Lu Gao, and Sarah Copeland at the Association of College and Research Libraries Conference in Cleveland, Ohio, on April 11, 2019. 


\section{Cultural Artifact}

A cultural artifact is anything created by humans that gives information about the culture of its creators and users:

An ancient Chinese landscape painting has been passed down in my family for generations. The painting shows peaceful scenery of beautiful mountains and rivers in the countryside. This special artwork inspired me to learn Chinese calligraphy during my childhood. Calligraphy is a fine art that requires persistence, patience, and aesthetic judgment. It brings my family and me joy in life and helps us stay optimistic when facing hardships.

Your turn: Take 3 minutes to think about, write about, or draw a personal artifact that you believe, in some small way, defines where you came from or who you are.

\section{Your Cultural Background}

How would you describe your own cultural background?

\section{Your Approach to Teaching}

Can you think of ways that your cultural background might affect your approach to teaching? Or your approach to librarianship?

\section{Assumptions}

What assumptions do you make about your students?

\section{Developing Mindful Practice}

Adapted from Geneva Gay's Culturally Responsive Teaching, 3rd ed. (New York: Teachers College Press, 2018), with our emphasis and descriptors:

- Critically self-reflect: Be critically cognizant of your attitudes, beliefs, and expectations about different ethnic, racial, and cultural groups, cultures, experiences, and issues, and track how they are manifested in instructional practices and relational behaviors.

- Pay attention: Learn to see, hear, and listen to diverse students, especially when they "speak" without words. Much can be learned by simply being present and paying close attention to students.

- Be authentic: Admit occurrences of fallibility, error, ignorance, and accomplishment in cultural diversity endeavors.

- Diversify: Diversify instructions and interactions. Caring teachers honor differences of and among students. They respond, in multiple ways, to the fact that students have different experiences, preferences, and capabilities.

- Remove barriers: Do not hold the academic achievement of ethnically diverse students hostage to the compromising or sacrificing of their cultural identities and heritages.

- Educate yourself: Work to learn about the diverse array of cultures present at your institution and in your community. 


\section{Notes}

1. Geneva Gay, Culturally Responsive Teaching: Theory, Research, and Practice, 3rd ed. (New York: Teachers College Press, 2018), 32.

2. Elizabeth Foster, "Cultural Competence in Library Instruction: A Reflective Practice Approach," portal: Libraries and the Academy 18, 3 (2018): 575, https: / / doi.org/10.1353/ pla.2018.0034.

3. Gay, Culturally Responsive Teaching, 8-12.

4. Foster, "Cultural Competence in Library Instruction."

5. Paulo Freire, Pedagogy of the Oppressed, trans. Myra Bergman Ramos (New York: Herder and Herder, 1970).

6. Gloria Ladson-Billings, "Toward a Theory of Culturally Relevant Pedagogy," American Educational Research Journal 32, 3 (1995): 465-91, https: / / doi. org / 10.3102/00028312032003465.

7. Gloria Ladson-Billings, The Dreamkeepers: Successful Teachers of African American Children (San Francisco: Jossey-Bass, 1994), 18.

8. Ladson-Billings, "Toward a Theory of Culturally Relevant Pedagogy," 484.

9. Liana Loewus, “White Women Still Dominate Teaching Force," Education Week 37, 1 (2017): 11.

10. National Center for Education Statistics, "Characteristics of Postsecondary Faculty," 2019, https: / / nces.ed.gov/programs/coe/indicator_csc.asp.

11. Patricia Larke, "Culturally Responsive Teaching in Higher Education: What Professors Need to Know," Counterpoints 391 (2013): 38.

12. Ladson-Billings, "Toward a Theory of Culturally Relevant Pedagogy."

13. Gloria Ladson-Billings, "But That's Just Good Teaching! The Case for Culturally Relevant Pedagogy," Theory into Practice 34, 3 (1995): 161-62.

14. Gay, Culturally Responsive Teaching.

15. James A. Banks, An Introduction to Multicultural Education (Boston: Allyn and Bacon, 1994).

16. Manning Marable, "Black Studies, Multiculturalism and the Future of American Education," in A Turbulent Voyage: Readings in African American Studies, ed. Floyd W. Hayes, 3rd ed. (San Diego: Rowman \& Littlefield, 2000), 25.

17. Gay, Culturally Responsive Teaching, 28-29.

18. Ibid., 42.

19. Howard Ball, S. D. Berkowitz, and Mbulelo Mzamane, Multicultural Education in Colleges and Universities: A Transdisciplinary Approach (Mahwah, NJ: Lawrence Erlbaum, 1998), x.

20. Margery B. Ginsberg and Raymond J. Wlodkowski, Diversity and Motivation: Culturally Responsive Teaching in College, 2nd ed. (San Francisco: Jossey-Bass, 2009).

21. Larke, "Culturally Responsive Teaching in Higher Education."

22. Annie Howell and Frank Tuitt, eds., Race and Higher Education: Rethinking Pedagogy in Diverse College Classrooms (Cambridge, MA: Harvard Education Publishing Group, 2003).

23. Lorri J. Santamaría and Andrés P. Santamaría, eds., Culturally Responsive Leadership in Higher Education: Promoting Access, Equity, and Improvement (New York: Routledge, 2016).

24. Sharlene Voogd Cochrane, Meenakshi Chhabra, Marjorie A. Jones, and Deborah Spragg, eds., Culturally Responsive Teaching and Reflection in Higher Education (New York: Routledge, 2017): v.

25. Judy Marquez Kiyama and Cecilia Rios-Aguilar, Funds of Knowledge in Higher Education: Honoring Students' Cultural Experiences and Resources as Strengths (New York: Routledge, 2018).

26. Lisa Sherff and Karen Spector, eds., Culturally Relevant Pedagogy: Clashes and Confrontations (Lanham, MD: Rowman \& Littlefield, 2011).

27. Alison Hicks, "Cultural Shifts: Putting Critical Information Literacy into Practice," Communications in Information Literacy 7, 1 (2013): 62, https: / / doi.org/10.15760/ comminfolit.2013.7.1.134. 
28. Kimberly Pendell and Robert Schroeder, "Librarians as Campus Partners: Supporting Culturally Responsive and Inclusive Curriculum," College \& Research Libraries News 78, 8 (2017): 416, https: / / doi.org/10.5860/ crln.78.8.414.

29. Amanda Folk, "Drawing on Students' Funds of Knowledge: Using Identity and Lived Experience to Join the Conversation in Research Assignments," Journal of Information Literacy 12, 2 (2018): 44-59, https: / / doi.org/10.11645/12.2.2468.

30. Foster, "Cultural Competence in Library Instruction," 575.

31. Gay, Culturally Responsive Teaching.

32. Ibid., 57-88.

33. Ibid., 80-81.

34. "Understanding Implicit Bias," Kirwan Institute for the Study of Race and Ethnicity, The Ohio State University, 2015, http:/ / kirwaninstitute.osu.edu/ research/ understandingimplicit-bias/.

35. Chapel Cowden, Priscilla Seaman, Lu Gao, and Sarah Copeland, "Promoting Learning in the Culturally Diverse Library Instruction Classroom," workshop at Association of College and Research Libraries Conference, Cleveland, OH, April 11, 2019.

36. Harvard University, "Project Implicit," 2011, https:/ / implicit.harvard.edu/implicit/ takeatest.html.

37. Char Booth, Reflective Teaching, Effective Learning: Instructional Literacy for Library Educators (Chicago: American Library Association, 2011), xi.

38. Gay, Culturally Responsive Teaching, 36.

39. Ibid., 140.

40. Ibid., 89 .

41. Ibid., 140 .

42. Ibid.

43. As cited in Norman B. Hutcherson, "Library Jargon: Student Recognition of Terms and Concepts Commonly Used by Librarians in the Classroom," College E Research Libraries 6, 4 (2004): 349-54, https:/ / doi.org/10.5860/crl.65.4.349.

44. Jian Wang and Donald G. Frank, "Cross-Cultural Communication: Implications for Effective Information Services in Academic Libraries," portal: Libraries and the Academy 2, 2 (2002): 211, https: / / doi.org/10.1353/pla.2002.0046.

45. Gay, Culturally Responsive Teaching, 141.

46. Ibid., 52, 140-41.

47. Harvard Graduate School of Education, “The Value of Listening," 2017, https:/ / gse. harvard.edu/news/uk/17/09/value-listening.

48. Gay, Culturally Responsive Teaching, 140.

49. Joshua Margolis in "The Value of Listening."

50. Frank Lyman, "The Responsive Classroom Discussion," in Mainstreaming Digest: A Collection of Faculty and Student Papers, ed. Audrey Springs Anderson (College Park, MD: University of Maryland, 1981), 109-13.

51. Jan Herrington, Thomas C. Reeves, and Ron Oliver, "Authentic Learning Environments," in Handbook of Research on Educational Communications and Technology, ed. J. Michael Spector, M. David Merrill, Jan Elen, and M. J. Bishop (New York: Springer-Verlag, 2014), 401-12.

52. Howard S. Barrows, "Problem-Based Learning in Medicine and Beyond: A Brief Overview," New Directions for Teaching \& Learning 68 (1996): 3-12, https: / / doi.org/10.1002/ tl.37219966804; Anne R. Diekema, Wendy Holliday, and Heather Leary, “Re-Framing Information Literacy: Problem-Based Learning as Informed Learning," Library and Information Science Research 33, 4 (2011): 261-68, https: / / doi.org/10.1016/j.lisr.2011.02.002; Ann Glusker, "Motivational Design and Problem-Based Learning May Increase Student Engagement in Information Literacy Instruction Sessions," Evidence Based Library $\mathcal{E}$ Information Practice 12, 4 (2017): 259-61, https: / / doi.org/10.18438/B8PQ1K; Lindsay Roberts, "Research in the Real World: Improving Adult Learners Web Search and Evaluation Skills through Motivational Design and Problem-Based Learning," College $\mathcal{E}$ Research Libraries 78, 4 (2017): 527-51, https:/ / doi.org/10.5860/ crl.78.4.527. 
53. Barrows, "Problem-Based Learning in Medicine and Beyond"; Howard S. Barrows, "A Taxonomy of Problem-Based Learning Methods," Medical Education 20, 6 (1986): 481-86, https: / / doi.org/10.1111/j.1365-2923.1986.tb01386.x; Cindy E. Hmelo-Silver and Howard S. Barrows, "Goals and Strategies of a Problem-Based Learning Facilitator," Interdisciplinary Journal of Problem-Based Learning 1, 1 (2006): 21-39, https: / / doi.org/10.7771/1541-

5015.1004; Andrew Walker and Heather Leary, "A Problem Based Learning Meta Analysis: Differences across Problem Types, Implementation Types, Disciplines, and Assessment Levels," Interdisciplinary Journal of Problem-Based Learning 3, 1 (2009): 12-43, https: / / doi. org/10.7771/1541-5015.1061.

54. Kadhir Rajagopal, Create Success: Unlocking the Potential of Urban Students (Alexandria, VA: Association for Supervision and Curriculum Development, 2011), cited in Gay, Culturally Responsive Teaching, 40.

55. Gay, Culturally Responsive Teaching, 40.

56. Ira Shor and Paulo Freire, A Pedagogy for Liberation: Dialogues on Transforming Education (South Hadley, MA: Bergin \& Garvey, 1987), 15-16.

57. Gay, Culturally Responsive Teaching, 245-46.

58. Larke, "Culturally Responsive Teaching in Higher Education."

59. American Evaluation Association, "American Evaluation Association Public Statement on Cultural Competence in Evaluation," 2011, https: / www.eval.org/p/cm/ld / fid=92.

60. Gay, Culturally Responsive Teaching, 153-60, 247. 
